\title{
Effect of partitioning the nonfiber carbohydrate fraction and neutral detergent fiber method on digestibility of carbohydrates by dairy cows
}

\author{
A. W. Tebbe, M. J. Faulkner, and W. P. Weiss ${ }^{1}$ \\ Department of Animal Sciences, Ohio Agricultural Research and Development Center, The Ohio State University, Wooster 44691
}

\begin{abstract}
Many nutrition models rely on summative equations to estimate feed and diet energy concentrations. These models partition feed into nutrient fractions and multiply the fractions by their estimated true digestibility, and the digestible mass provided by each fraction is then summed and converted to an energy value. Nonfiber carbohydrate (NFC) is used in many models. Although it behaves as a nutritionally uniform fraction, it is a heterogeneous mixture of components. To reduce the heterogeneity, we partitioned NFC into starch and residual organic matter (ROM), which is calculated as 100 - CP - LCFA - ash - starch - NDF, where crude protein (CP), long-chain fatty acids (LCFA), ash, starch, and neutral detergent fiber (NDF) are a percentage of DM. However, the true digestibility of ROM is unknown, and because NDF is contaminated with both ash and CP, those components are subtracted twice. The effect of ash and CP contamination of NDF on in vivo digestibility of NDF and ROM was evaluated using data from 2 total-collection digestibility experiments using lactating dairy cows. Digestibility of NDF was greater when it was corrected for ash and $\mathrm{CP}$ than without correction. Conversely, ROM apparent digestibility decreased when NDF was corrected for contamination. Although correcting for contamination statistically increased NDF digestibility, the effect was small; the average increase was $3.4 \%$. The decrease in ROM digestibility was $7.4 \%$. True digestibility of ROM is needed to incorporate ROM into summative equations. Data from multiple digestibility experiments (38 diets) using dairy cows were collated, and ROM concentrations were regressed on concentration of digestible ROM (ROM was calculated without adjusting for ash and $\mathrm{CP}$ contamination). The estimated true digestibility coefficient of ROM was $0.96(\mathrm{SE}=0.021)$, and metabolic fecal ROM was $3.43 \mathrm{~g} / 100 \mathrm{~g}$ of dry matter intake $(\mathrm{SE}=0.30)$. Using a smaller data set (7 diets), estimated true digestibility of ROM when calculated
\end{abstract}

Received February 13, 2017.

Accepted April 6, 2017.

${ }^{1}$ Corresponding author: weiss.6@osu.edu using NDF corrected for ash and $\mathrm{CP}$ contamination was $0.87(\mathrm{SE}=0.025)$, and metabolic fecal $\mathrm{ROM}$ was $3.76 \mathrm{~g} / 100 \mathrm{~g}(\mathrm{SE}=0.60)$. Regardless of NDF method, ROM exhibited nutritional uniformity. The ROM fraction also had lower errors associated with the estimated true digestibility and its metabolic fecal fraction than did NFC. Therefore, ROM may result in more accurate estimates of available energy if integrated into models. Key words: starch, nonfiber carbohydrate, neutral detergent fiber, digestibility

\section{INTRODUCTION}

Diets for dairy cows comprise predominantly carbohydrates, but this fraction is too chemically and nutritionally heterogeneous to be of value for estimating the available energy concentration of feeds. To partially overcome this problem, many energy models (including NRC, 2001) separate carbohydrates into 2 broad fractions: NFC with a fixed digestibility coefficient (e.g., 0.98 at maintenance in NRC, 2001) and NDF with a variable digestibility based on lignin (ranging from about 0.3 to 0.6 ). Although this is an improvement over a single carbohydrate fraction, considerable heterogeneity still exists within these fractions.

Starch is a major component of the NFC fraction and is now routinely assayed in feeds for use in ration formulation programs. Starch can range from 65 to $75 \%$ of the NFC fraction for typical forage-based diets and from 45 to $55 \%$ for diets high in by-products. Across diets, total-tract starch digestibility is not constant and ranges from about 0.85 to 0.99 in lactating dairy cows (Ferraretto et al., 2013). Many sources of the variation are known and have been quantified (Firkins, 2006; Ferraretto et al., 2013; Allen and Piantoni, 2014). Therefore, removing starch from NFC and applying feed-specific (e.g., based on particle size of corn grain) digestibility coefficients to the starch fraction may reduce the nutritional heterogeneity of the NFC fraction.

Other minor components of the NFC fraction include sugars, soluble fibers (e.g., $\beta$-glucans, pectin), and organic acids. However, the methods for quantifying many of these minor components are complex (Kagan et al., 2014), lack appropriate standards, and are expensive 
(Hall, 2003, 2014). Therefore, rather than fractioning nonstarch NFC, an aggregated fraction termed residual OM $(\mathbf{R O M})$ is calculated as

$$
\begin{aligned}
\mathrm{ROM}= & 100-\mathrm{CP}-\mathrm{LCFA}-\mathrm{ash} \\
& - \text { starch }-\mathrm{NDF},
\end{aligned}
$$

where LCFA = long-chain fatty acids and all values are expressed as a percentage of DM.

By calculating ROM by difference, a large volume of digestibility data previously generated can be used, but an estimate of its true digestibility is needed before ROM can be incorporated into summative equations. However, similar to NFC, ROM has flaws: (1) it is not measured directly and accumulates the errors of analyzing other fractions; (2) it contains a multitude of compounds, including lipid backbones, soluble fiber, sugars, nucleic acids, vitamins, pigments, and waxes; and (3) NDF contains variable amounts of ash and CP, leading to the double subtraction of neutral detergent insoluble $\mathrm{CP}$ and ash when ROM is calculated. In most feeds, ash composes 1 to $3 \%$ of the NDF (Mertens, 2002 ) but can exceed $7 \%$ of the NDF in some diets (Crocker et al., 1998). Likewise, CP makes up 2 to $10 \%$ of NDF but can be more than $20 \%$ of the NDF in some by-product feeds (NRC, 2001). Concentrations of ash and CP-free NDF and the resulting ROM fraction can be easily measured, but the effects of removing $\mathrm{CP}$ and ash contamination on NDF and ROM digestibility have not been extensively evaluated.

Therefore, the first objective of this project was to determine whether correcting for ash and CP contamination in NDF affected apparent digestibility of NDF and ROM by lactating dairy cows and whether this correction would affect statistical inferences of treatment (i.e., diet) effects on digestibility. The second objective of this experiment was to estimate the true digestibility and metabolic fecal ROM and to determine whether those variables were affected by ash and $\mathrm{CP}$ contamination of NDF. This information is needed so that ROM can be incorporated into energy equations.

\section{MATERIALS AND METHODS}

All procedures used on animals in these experiments were approved by The Ohio State University Institutional Animal Care and Use Committee.

\section{Data}

Retained feed, fecal, and refusal samples from 2 total collection digestibility experiments conducted at the Ohio Agricultural Research and Development Center were used (Faulkner and Weiss, 2017; W. P. Weiss, Ohio Agricultural Research and Development Center, unpublished data). Each sample was a composite of 4 daily samples taken during the collection trials; additional sampling details are presented in Weiss et al. (2009). The samples had been frozen, lyophilized, and ground through a 1-mm screen (Wiley mill; Arthur A. Thomas Co., Philadelphia, PA). Ground samples were analyzed for NDF (Ankom200 Fiber Analyzer; Ankom Technology Corp., Fairport, NY) in quadruplicate with sodium sulfite and amylase (Sigma A3306; Sigma-Aldrich, St. Louis, MO). Two of the 4 NDF residues were ashed in a muffle oven (NDI-ash) at $600^{\circ} \mathrm{C}$ overnight to calculate ash-free NDF ( $\left.\mathbf{N D F}_{\mathbf{o m}}\right)$, and 2 of the NDF residues were analyzed for neutral detergent insoluble $\mathrm{CP}(\mathrm{NDICP})$ using the Kjeldahl method $(\mathrm{N} \times 6.25)$ to calculate $\mathrm{CP}$-free $\mathrm{NDF}\left(\mathbf{N D F}_{\mathbf{c p}}\right)$. The NDI-ash and NDICP values were then combined to calculate ash- and CP-free NDF ( $\left.\mathbf{N D F}_{\text {om+cp }}\right)$. Concentrations of DM, OM, CP, starch, and long-chain fatty acids were analyzed as previously described (Weiss et al., 2009). Residual OM was calculated as

$$
\begin{aligned}
\mathrm{ROM}_{\mathrm{x}}= & 100-\mathrm{CP}-\mathrm{LCFA}-\text { ash } \\
& - \text { starch }-\mathrm{NDF}_{\mathrm{x}},
\end{aligned}
$$

where all values are expressed as a percentage of $\mathrm{DM}, \mathrm{ROM}_{\mathrm{x}}$ was calculated using the 4 different NDF methods, and $\mathrm{NDF}_{\mathrm{x}}$ was from the 4 different methods (i.e., $\mathrm{NDF}, \mathrm{NDF}_{\mathrm{om}}, \mathrm{NDF}_{\mathrm{cp}}$, and $\mathrm{NDF}_{\mathrm{om}+\mathrm{cp}}$ ). Total-tract digestibilities were then calculated for the 4 different NDF fractions and the 4 different resulting ROM fractions.

Experiment 1 (Faulkner and Weiss, 2017) was designed to examine interactions between source of fiber (conventional forage-based diet or by-product-based diet) and source of supplemental trace minerals (sulfate or hydroxy; Micronutrients Inc., Indianapolis, IN) on nutrient digestibility. The experiment was a split-plot, Latin square design (fiber was whole plot, minerals was split plot) with 9 cow periods per dietary treatment. Experiment 2 was designed to determine digestibility of nutrients from diets comprising silage made from 3 different corn hybrids (W. P. Weiss, unpublished data): a conventional dual-purpose corn (Hy-A), a brown midrib corn $(\mathrm{Hy}-\mathrm{B})$, and an experimental brown midrib corn (Hy-C). The experiment was a replicated, incomplete $3 \times 2$ Latin square with 4 cows per treatment. Ingredients and chemical composition for the diets and ingredients are shown in Tables 1-5.

The ROM calculated from experiments 1 and 2 was combined with data generated from 8 other experiments conducted at the Ohio Agricultural Research 
TEBBE ET AL.

Table 1. Ingredient and nutrient composition of the diets

\begin{tabular}{|c|c|c|c|c|c|}
\hline \multirow[b]{2}{*}{ Item } & \multicolumn{2}{|c|}{ Experiment $1^{1}$} & \multicolumn{3}{|c|}{ Experiment $2^{2}$} \\
\hline & Conventional & By-product & Hy-A & Hy-B & $\mathrm{Hy}-\mathrm{C}$ \\
\hline \multicolumn{6}{|l|}{ Ingredient } \\
\hline Corn silage & 44.0 & 20.0 & 45.0 & 45.0 & 45.0 \\
\hline Alfalfa silage & 20.0 & 15.0 & 11.0 & 11.0 & 11.0 \\
\hline Ground corn & 18.5 & - & 7.41 & 10.6 & 11.1 \\
\hline Soybean meal, $48 \% \mathrm{CP}$ & 14.9 & 8.5 & 15.5 & 16.4 & 16.5 \\
\hline Distillers grains & - & - & 5.02 & 4.97 & 4.90 \\
\hline Rolled oats & - & 14.3 & - & - & - \\
\hline Dried corn gluten feed & - & 11.0 & - & - & - \\
\hline Dried beet pulp & - & 15.0 & - & - & - \\
\hline Soy hulls & - & 14.1 & 12.7 & 8.67 & 8.10 \\
\hline Animal or vegetable fat & 0.51 & 0.65 & 0.44 & 0.48 & 0.44 \\
\hline Vitamins and minerals & 2.09 & 1.45 & 2.93 & 2.88 & 2.96 \\
\hline \multicolumn{6}{|l|}{ Nutrient, ${ }^{3} \%$} \\
\hline DM & 55.0 & 71.6 & 62.5 & 61.6 & 60.7 \\
\hline Starch & 35.4 & 17.6 & 23.7 & 22.3 & 23.0 \\
\hline $\mathrm{CP}$ & 14.3 & 14.8 & 16.5 & 17.0 & 17.3 \\
\hline NDICP & 0.89 & 2.03 & 1.52 & 1.30 & 1.31 \\
\hline NDI-ash & 0.62 & 1.34 & 0.80 & 0.75 & 0.69 \\
\hline LCFA & 3.66 & 3.54 & 3.52 & 3.53 & 3.52 \\
\hline Ash & 6.25 & 7.23 & 6.75 & 6.89 & 6.48 \\
\hline
\end{tabular}

${ }^{1}$ Dietary treatments: conventional forage fiber diet or by-product fiber diet with supplemental $\mathrm{Cu}, \mathrm{Zn}$, and $\mathrm{Mn}$ from sulfate or hydroxy mineral sources.

${ }^{2}$ Conventional dual-purpose corn (Hy-A), a brown midrib corn (Hy-B), and an experimental brown midrib corn (Hy-C).

${ }^{3} \mathrm{NDICP}=$ neutral detergent insoluble CP; NDI-ash $=$ neutral detergent insoluble ash; LCFA = long-chain fatty acids.

and Development Center, resulting in 214 cow periods representing 36 dietary treatments (referred to as the full data set). Most studies used Latin square type designs, and digestibility was measured using the protocol outlined in Weiss et al. (2009). Samples were no longer available; therefore, ROM was calculated using only the standard NDF method. Objectives varied across experiments and included evaluation of forage sources, by-product diets, sources of supplemental fat, and mineral supplementation. Generally, the diets met or exceeded NRC (2001) recommendations for CP, fiber, and minerals.

\section{Calculations and Statistical Analysis}

Data were analyzed using PROC MIXED (SAS Institute, 2015) to evaluate the effect of NDF method and its interaction with dietary treatments on NDF and ROM apparent digestibility. For experiment 1, the model included the fixed effects of fiber $(1 \mathrm{df})$, mineral source (1 df), and NDF method (3 df); the 2- and 3-way interactions of the fixed effects; and the random effects of group ( $2 \mathrm{df})$, period within group ( $2 \mathrm{df})$, cow within group $\times$ fiber $(12 \mathrm{df})$, cow $\times$ group $\times$ fiber $\times$ period, and residual error. No 3 -way interactions of fixed effects were significant $(P>0.10)$. For experiment 2 , the model included the fixed effects of hybrid ( $2 \mathrm{df}$ ), period $(1 \mathrm{df})$, and method ( $3 \mathrm{df})$ and the random effects of cow $(5 \mathrm{df})$ and interaction of cow $\times$ hybrid $\times$ period $(10$ df). For both models, degrees of freedom were adjusted using the Kenward-Roger approximation. Interactions of fixed effects were evaluated using the SLICE option, and if significant $(P<0.05)$, means were separated by Fisher's least significant difference test. Because NDF methods are highly correlated and inherently measured on the same observation, the fixed effect of method was also evaluated as a repeated measure with an autoregressive covariance structure but produced almost identical results and was not further investigated.

\section{Estimating the True Digestibility of ROM}

True digestibility and metabolic fecal excretion of ROM calculated using the standard NDF method of the full data set were estimated using the Lucas test (Van Soest, 1994). Cow period data $(\mathrm{n}=214)$ were used in the regression of concentration of digestible ROM on concentration of ROM using PROC MIXED with experiment and period within an experiment as random class effects (St-Pierre, 2001). The intercept and slope from the regression are estimates of metabolic fecal $\mathrm{ROM}$ and the true digestibility of ROM, respectively 
Table 2. Concentrations of dietary carbohydrate fractions and digestibility coefficients using 4 different NDF methods (experiment 1)

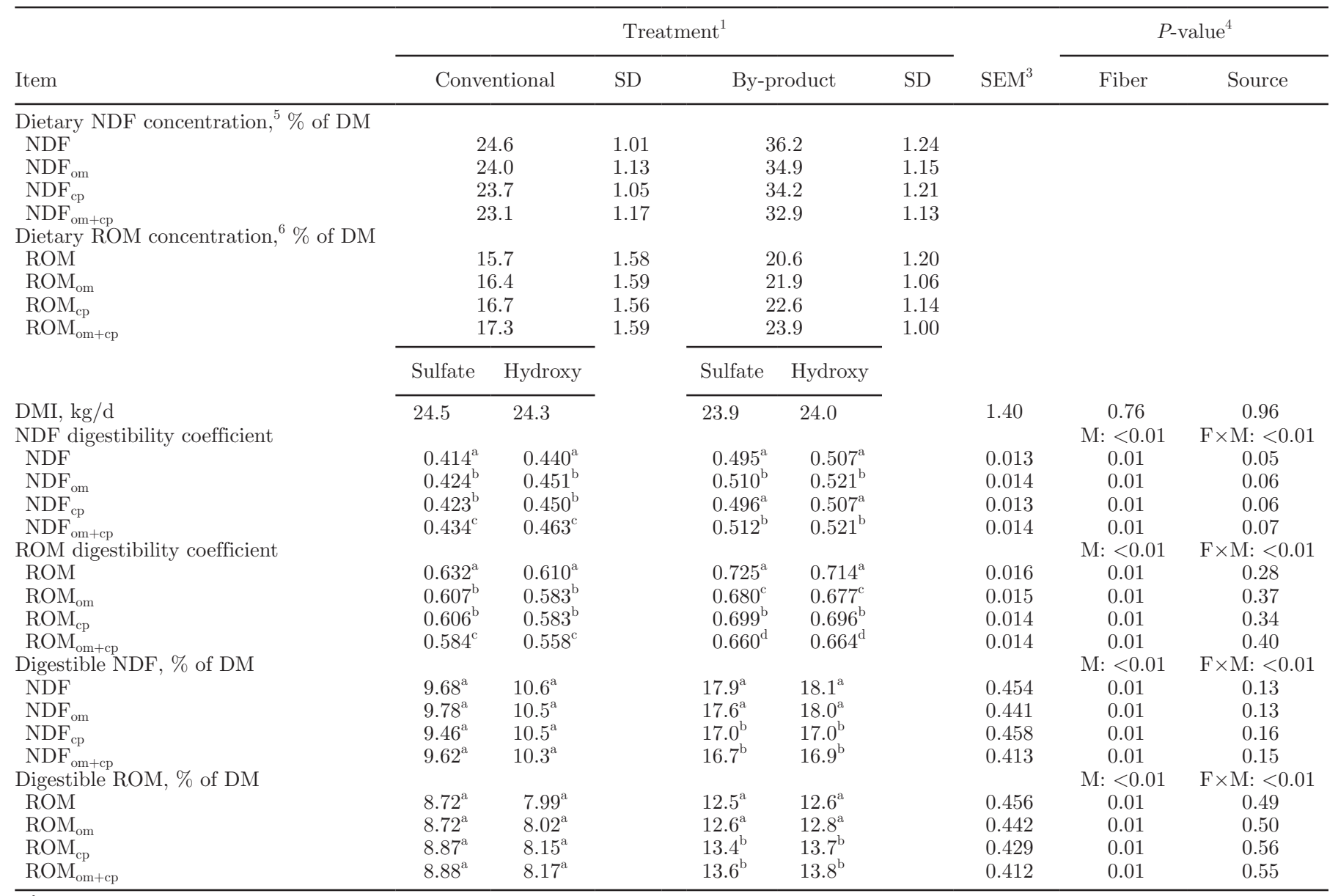

${ }^{\mathrm{a}-\mathrm{d}}$ Values within the same column, dietary treatment, and NDF or residual OM (ROM) digestion measurement with the same superscripts are similar $(P>0.05)$.

${ }^{1}$ Conventional sulfate or hydroxy $=$ conventional forage fiber diet with supplemental $\mathrm{Cu}$, Zn, and Mn from sulfate or hydroxy mineral sources. By-product sulfate or hydroxy = by-product fiber diet with supplemental $\mathrm{Cu}, \mathrm{Zn}$, and $\mathrm{Mn}$ from sulfate or hydroxy mineral sources.

${ }^{2}$ Standard deviations of concentrations determined by Monte Carlo simulation.

${ }^{3}$ Data were unbalanced because of 1 missing observation; therefore, the greatest SEM values were reported.

${ }^{4}$ Where $\mathrm{M}=P$-value for method; $\mathrm{F} \times \mathrm{M}=P$-value for fiber $\times$ method interaction.

${ }^{5} \mathrm{NDF}=\mathrm{NDF}$ analysis with amylase and sulfite; $\mathrm{NDF}_{\mathrm{om}}=\mathrm{NDF}-\mathrm{NDI}-\mathrm{ash} ; \mathrm{NDF}_{\mathrm{cp}}=\mathrm{NDF}-\mathrm{NDICP} ; \mathrm{NDF}$ om $+\mathrm{cp}=\mathrm{NDF}-\mathrm{NDI}-\mathrm{ash}-\mathrm{NDICP}$. $\left(\mathrm{NDI}-\mathrm{ash}=\mathrm{NDF}\right.$ residues ashed in a muffle oven at $600^{\circ} \mathrm{C}$ overnight; NDICP $=$ neutral detergent insoluble CP.)

${ }^{6} \mathrm{ROM}_{\mathrm{x}}(\%$ of DM $)=100-\% \mathrm{CP}-\%$ long-chain fatty acids $-\%$ ash $-\%$ starch $-\% \mathrm{NDF}_{\mathrm{x}}$, where $\mathrm{x}=$ NDF method.

(Van Soest, 1994). The same data and NDF method were used in regressions with digestible NFC and NFC (calculated as 100 - NDF - CP - LCFA - ash) and digestible starch and starch. The slopes and intercepts of these regressions (ROM, NFC, and starch) were compared using paired $t$-tests. The same regression analyses using ROM calculated with each of the 4 different NDF methods (experiments 1 and 2 only) were also conducted to determine the effect of NDF method on true digestibility of ROM. The Y-intercepts of the 4 regressions were the same $(P>0.19)$, so a common intercept model was used to estimate true digestibility of ROM for each method. Slopes were evaluated using contrast statements (effect of ash correction, effect of $\mathrm{CP}$ correction, and $\mathrm{NDF}_{\text {om }} \mathrm{vs} \mathrm{NDF}_{\mathrm{cp}}$ ). Simple statistics for the full data set were calculated using PROC UNIVARIATE (Table 6).

\section{RESULTS AND DISCUSSION}

\section{Composition}

The ROM concentration of corn silage ranged from about 12 to $16 \%$ of DM; concentrations in alfalfa silage were higher, ranging from about 20 to $30 \%$ (Table 4). Concentrations of ROM in predominantly corn grain 
Table 3. Concentrations of diet carbohydrate fractions and digestibility coefficients using 4 different NDF methods (experiment 2)

\begin{tabular}{|c|c|c|c|c|c|c|c|c|}
\hline Item & \multicolumn{6}{|c|}{$\operatorname{Diet}^{1}$} & SEM & Hybrid $P$-value ${ }^{2}$ \\
\hline \multicolumn{9}{|c|}{ Dietary NDF concentrations, ${ }^{4} \%$ of DM } \\
\hline $\mathrm{NDF}_{\text {om }}$ & 33.6 & 1.44 & 32.4 & 1.20 & 32.8 & 1.39 & & \\
\hline $\mathrm{NDF}_{\mathrm{cp}}$ & 32.9 & 1.10 & 31.8 & 1.05 & 32.1 & 1.20 & & \\
\hline $\mathrm{NDF}_{\mathrm{om}+\mathrm{cp}}^{\mathrm{cp}}$ & 32.1 & 1.07 & 31.1 & 0.97 & 31.4 & 1.08 & & \\
\hline $\mathrm{ROM}_{\mathrm{om}}$ & 15.9 & 1.39 & 17.9 & 0.63 & 17.0 & 0.54 & & \\
\hline $\mathrm{ROM}_{\mathrm{cp}}$ & 16.6 & 1.90 & 18.4 & 1.00 & 17.6 & 0.86 & & \\
\hline $\mathrm{ROM}_{\mathrm{om}+\mathrm{cp}}$ & 17.4 & 1.84 & 19.2 & 0.85 & 18.3 & 0.86 & & \\
\hline DMI, $\mathrm{kg} / \mathrm{d}$ & 25.5 & & 25.9 & & 25.6 & & 1.53 & 0.96 \\
\hline NDF digestibility coefficient & & & & & & & & $\mathrm{M}:<0.01$ \\
\hline $\mathrm{NDF}^{\mathrm{a}}$ & 0.532 & & 0.511 & & 0.527 & & 0.033 & 0.75 \\
\hline $\mathrm{NDF}_{\text {om }}{ }^{\mathrm{b}}$ & 0.539 & & 0.516 & & 0.534 & & 0.034 & 0.68 \\
\hline $\mathrm{ROM}_{\mathrm{cp}}^{\mathrm{c}}$ & 0.703 & & 0.751 & & 0.706 & & 0.035 & 0.68 \\
\hline $\mathrm{ROM}_{\mathrm{om}+\mathrm{cp}}^{\mathrm{cd}}$ & 0.695 & & 0.723 & & 0.708 & & 0.025 & 0.77 \\
\hline Digestible NDF, $\%$ of DM & & & & & & & & $\mathrm{M}:<0.01$ \\
\hline $\mathrm{NDF}^{\mathrm{a}}$ & 17.9 & & 16.8 & & 17.4 & & 1.08 & 0.59 \\
\hline $\mathrm{NDF}_{\mathrm{om}}{ }^{\mathrm{a}}$ & 17.8 & & 16.5 & & 17.3 & & 1.13 & 0.48 \\
\hline $\mathrm{NDF}_{\mathrm{cp}}^{\mathrm{b}}$ & 17.5 & & 16.5 & & 16.9 & & 1.37 & 0.60 \\
\hline $\mathrm{NDF}_{\mathrm{om}+\mathrm{cp}}^{\mathrm{b}}$ & 17.3 & & 16.2 & & 16.8 & & 1.36 & 0.54 \\
\hline Digestible ROM, $\%$ of DM & & & & & & & & $\mathrm{M}:<0.01$ \\
\hline $\mathrm{ROM}^{\mathrm{a}}$ & 11.4 & & 13.6 & & 12.4 & & 0.571 & 0.19 \\
\hline $\mathrm{ROM}_{\mathrm{om}}{ }^{\mathrm{a}}$ & 11.4 & & 13.8 & & 12.5 & & 0.380 & 0.06 \\
\hline $\mathrm{ROM}_{\mathrm{cp}}^{\mathrm{ab}}$ & 11.5 & & 14.0 & & 12.7 & & 0.486 & 0.06 \\
\hline $\mathrm{ROM}_{\mathrm{om}+\mathrm{cp}}^{\mathrm{c}}$ & 12.0 & & 14.1 & & 13.1 & & 0.342 & 0.07 \\
\hline
\end{tabular}

\footnotetext{
a-d NDF methods within an NDF or residual OM (ROM) measure with similar superscript letters do not differ $(P>0.05)$.

${ }^{1}$ Conventional dual-purpose corn (Hy-A), a brown midrib corn (Hy-B), and an experimental brown midrib corn (Hy-C).

${ }^{2}$ Where $\mathrm{M}=P$-value for method.

${ }^{3}$ Standard deviations of concentrations determined by Monte Carlo simulation.

${ }^{4} \mathrm{NDF}=\mathrm{NDF}$ analysis with amylase and sulfite; $\mathrm{NDF}_{\mathrm{om}}=\mathrm{NDF}-\mathrm{NDI}-\mathrm{ash} ; \mathrm{NDF}_{\mathrm{cp}}=\mathrm{NDF}-\mathrm{NDICP} ; \mathrm{NDF}{ }_{\mathrm{om}+\mathrm{cp}}=\mathrm{NDF}-\mathrm{NDI}-\mathrm{ash}-\mathrm{NDICP}$. $\left(\mathrm{NDI}-\mathrm{ash}=\mathrm{NDF}\right.$ residues ashed in a muffle oven at $600^{\circ} \mathrm{C}$ overnight; NDICP $=$ neutral detergent insoluble CP.

${ }^{5} \mathrm{ROM}_{\mathrm{x}}(\%$ of $\mathrm{DM})=100-\% \mathrm{CP}-\%$ long-chain fatty acids $-\%$ ash $-\%$ starch $-\% \mathrm{NDF}_{\mathrm{x}}$, where $\mathrm{x}=$ NDF method.
}

and soybean meal mixes averaged about $10 \%$ and more than $20 \%$ in concentrates based on high-fiber by-products (Table 5). For alfalfa silage, concentrations of NFC and ROM were similar, but ROM was substantially smaller than NFC for corn silage and the concentrates. The smaller concentration of ROM compared with NFC will reduce the influence this fraction has on estimated energy values. Because of the heterogeneous nature of both NFC and ROM, a smaller fraction may result in less error when estimating energy.

When correcting for ash and $\mathrm{CP}$, the change in NDF or ROM concentrations was not constant. Corrections had a greater effect for alfalfa than for corn silage and a greater effect for by-product-based concentrate mixes than for corn- and soybean-based mixes (Tables 4 and $5)$. The NDI-ash of forages typically ranges from about 15 to $25 \%$ of the total ash content but can differ based on the amount of soil contamination or harvesting methods (Mertens, 2016). The NDICP content of forages is also dissimilar (5-40\% of the total CP; Krishnamoorthy et al., 1982) and is affected by heat damage (Weiss et al., 1986), kernel processing (Weiss and Wyatt, 2000), plant varieties, maturities, and growing conditions (Valk et al., 1996; Nordheim-Viken and Volden, 2009). In this study, the NDICP averaged 1.9 and $7.6 \%$ of total NDF for corn silage and alfalfa silage, respectively, and NDI-ash averaged 1.6 and $4.6 \%$ of the total NDF, respectively. For corn silages, correcting for CP or ash contamination was similar quantitatively, but for concentrates, correcting for CP contamination typically had a greater effect on NDF (and subsequent ROM) than did correcting for ash. The contamination of NDF by $\mathrm{CP}$ was much greater than ash in the alfalfa silage in experiment 2, but ash and $\mathrm{CP}$ contamination were 
DIGESTIBILITY OF CARBOHYDRATES BY DAIRY COWS

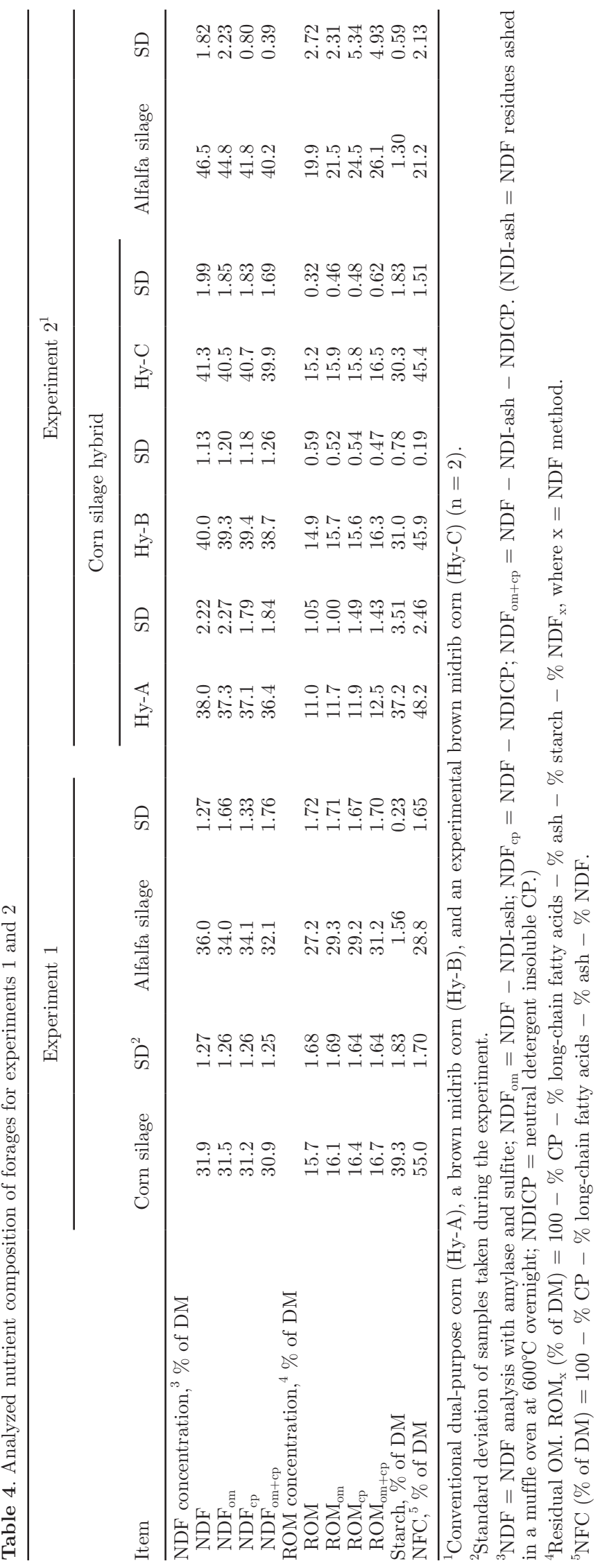


Table 5. Nutrient composition of concentrate mixes for experiments 1 and 2

\begin{tabular}{|c|c|c|c|c|c|c|c|c|c|c|}
\hline Item & \multicolumn{4}{|c|}{ Experiment $1^{1}$} & \multicolumn{6}{|c|}{ Experiment $2^{2}$} \\
\hline NDF & 9.4 & 0.55 & 37.6 & 1.22 & 27.7 & 0.42 & 22.7 & 1.10 & 22.2 & 0.74 \\
\hline $\mathrm{NDF}_{\mathrm{om}}$ & 9.2 & 0.69 & 36.1 & 1.00 & 27.0 & 0.39 & 22.1 & 0.93 & 21.8 & 0.70 \\
\hline $\mathrm{NDF}_{\mathrm{cp}}$ & 8.8 & 0.62 & 35.2 & 1.17 & 26.3 & 0.47 & 21.5 & 0.99 & 21.0 & 0.66 \\
\hline $\mathrm{ROM}$ & 9.4 & 1.38 & 20.5 & 0.92 & 18.1 & 1.52 & 18.7 & 0.49 & 16.6 & 0.21 \\
\hline $\mathrm{ROM}_{\mathrm{om}}$ & 9.6 & 1.40 & 22.0 & 0.71 & 18.8 & 1.54 & 19.2 & 0.33 & 17.0 & 0.17 \\
\hline $\mathrm{ROM}_{\mathrm{cp}}$ & 10.1 & 1.43 & 23.0 & 0.86 & 19.5 & 1.47 & 19.8 & 0.39 & 17.8 & 0.13 \\
\hline $\mathrm{ROM}_{\mathrm{om}+\mathrm{cp}}$ & 10.3 & 1.46 & 24.5 & 0.65 & 20.2 & 1.49 & 20.3 & 0.22 & 18.2 & 0.09 \\
\hline Starch, $\%$ of DM & 49.4 & 1.51 & 14.7 & 0.21 & 15.5 & 1.80 & 18.8 & 0.35 & 20.9 & 0.79 \\
\hline $\mathrm{NFC}^{5} \%$ of DM & 58.9 & 0.71 & 35.2 & 0.82 & 33.6 & 0.27 & 37.5 & 0.84 & 37.4 & 0.59 \\
\hline
\end{tabular}

${ }^{1}$ Conventional concentrate fed in a typical-forage-based diet; By-product concentrate fed in a low forage, high by-product-based diet ( $\mathrm{n}=6$ ).

${ }^{2}$ Conventional dual-purpose corn (Hy-A), a brown midrib corn (Hy-B), and an experimental brown midrib corn (Hy-C) ( $\left.\mathrm{n}=2\right)$.

${ }^{3} \mathrm{NDF}=\mathrm{NDF}$ analysis with amylase and sulfite; $\mathrm{NDF}_{\mathrm{om}}=\mathrm{NDF}-\mathrm{NDI}$-ash; $\mathrm{NDF}_{\mathrm{cp}}=\mathrm{NDF}-\mathrm{NDICP} ; \mathrm{NDF}_{\mathrm{om}+\mathrm{cp}}=\mathrm{NDF}-\mathrm{NDI}-\mathrm{ash}-\mathrm{NDICP}$ $\left(\mathrm{NDI}-\right.$ ash $=\mathrm{NDF}$ residues ashed in a muffle oven at $600^{\circ} \mathrm{C}$ overnight; NDICP $=$ neutral detergent insoluble CP. $)$

${ }^{4}$ Residual $\mathrm{OM} . \mathrm{ROM}_{\mathrm{x}}(\%$ of $\mathrm{DM})=100-\% \mathrm{CP}-\%$ long-chain fatty acids $-\%$ ash $-\%$ starch $-\%$ NDF , where $\mathrm{x}=\mathrm{NDF}$ method.

${ }^{5} \mathrm{NFC}(\%$ of DM $)=100-\% \mathrm{CP}-\%$ long-chain fatty acids $-\%$ ash $-\% \mathrm{NDF}$.

almost identical in the alfalfa silage used in experiment 1. The alfalfa silage in experiment 2 was drier ( 54.4 vs. $39.8 \% \mathrm{DM})$, which is related to increased heat damage.

The full correction (CP and ash) decreased NDF on average $3.6 \%$ for corn silages and $13.9 \%$ for alfalfa silages, whereas the average increase for ROM was 8.6 and $18.3 \%$, respectively (Table 4). For concentrate mixes, the full correction reduced NDF content by $9.0 \%$, whereas the average increase in ROM was $10.3 \%$ (Table 5). The percentage change varied based on the amount of by-products in the concentrate mixes (es-

Table 6. Descriptive statistics of the full data set $(n=214$ cow observations from 36 treatment means)

\begin{tabular}{lccc}
\hline Item & Mean & SD & $\begin{array}{c}\text { 10th-90th } \\
\text { percentile }\end{array}$ \\
\hline Concentration, \% of DM & & & \\
NDF $^{1}$ & 33.3 & 7.40 & $24.4-39.2$ \\
CP & 16.1 & 2.03 & $13.6-18.1$ \\
Ash & 6.40 & 0.65 & $7.31-5.67$ \\
Long-chain fatty acids & 3.96 & 1.22 & $2.87-5.87$ \\
Starch & 27.0 & 5.69 & $18.2-35.0$ \\
NFC $^{2}$ & 40.3 & 5.98 & $33.8-48.8$ \\
ROM & 13.2 & 4.11 & $7.58-18.3$ \\
DMI, kg & 22.2 & 4.38 & $15.8-26.9$ \\
Digestibility coefficient & & & \\
DM & 0.666 & 0.032 & $0.626-0.705$ \\
Starch & 0.912 & 0.043 & $0.857-0.971$ \\
NFC & 0.841 & 0.047 & $0.784-0.898$ \\
ROM & 0.651 & 0.260 & $0.473-0.825$ \\
\hline
\end{tabular}

${ }^{1} \mathrm{NDF}=\mathrm{NDF}$ analysis with amylase and sulfite.

${ }^{2} \mathrm{NFC}(\%$ of $\mathrm{DM})=(100-\% \mathrm{CP}-\%$ long-chain fatty acids $-\%$ ash $-\% \mathrm{NDF})$.

${ }^{3}$ Residual OM $(\%$ of DM $)=(100-\% \mathrm{CP}-\%$ long-chain fatty acids $-\%$ ash $-\%$ starch - \% NDF). pecially distillers grains and corn gluten feed) because of their large NDICP content (Krishnamoorthy et al., 1982; DePeters et al., 1997).

In experiment 1 , total dietary NDF concentration decreased 6.5 and $10.0 \%$ for the conventional and by-product-based diets, respectively, when ash and CP contamination was removed. Conversely, ROM increased 11.8 and $13.8 \%$, respectively. In experiment 2 , the total diet NDF concentration decreased $6.7 \%$ on average and ROM content increased $11.7 \%$, similarly to the conventional diet. Overall, with full correction of ash and CP contamination, NDF concentration decreased about 2 percentage units with a concomitant increase in ROM concentration.

\section{Digestibility}

Type of NDF method affected $(P<0.01)$ the digestibility of NDF and ROM (Tables 2 and 3). In all diets, digestibility of NDF was less $(P<0.05)$ than digestibility of $\mathrm{NDF}_{\mathrm{om}}$ and $\mathrm{NDF}_{\text {om+cp }}$ (Tables 2 and 3 ). Crocker et al. (1998) also reported that digestibility of $\mathrm{NDF}_{\text {om }}$ was greater than digestibility of NDF, and for most of their diets the differences were quantitatively similar to the differences we observed. Differences between digestibility of NDF and $\mathrm{NDF}_{\mathrm{cp}}$ were not consistent across diets. Digestibility of NDF and $\mathrm{NDF}_{\mathrm{cp}}$ were similar for by-product-based diets in experiment 1 , but digestibility of $\mathrm{NDF}_{\mathrm{cp}}$ was greater $(P<0.05)$ than $\mathrm{NDF}$ digestibility for the other diets in experiments 1 and 2 (i.e., method $\times$ fiber source treatment interaction for experiment $1 ; P<0.01$ ). The effect of NDF method 
on ROM digestibility was the opposite of what was observed for NDF.

Although the effect of method on NDF and ROM digestibility was statistically significant, quantitatively the effects were not great. Adjusting for both ash and $\mathrm{CP}$ resulted in the greatest increase in NDF digestibility. However, even full correction increased NDF digestibility only by 2.4 to $5 \%$ (average correction across diets $=3.4 \%$ ) compared with uncorrected NDF. Full correction of NDF resulted in a 6.5 to $9 \%$ increase in ROM apparent digestibility (average increase $=7.4 \%$ ). Correcting NDF for ash and CP contamination did not have a substantial average effect on NDF digestibility. However, the observed NDF method $\times$ diet interactions on NDF and ROM digestibility limit extrapolation of that conclusion to diverse diets.

The effects of removing ash and CP from NDF on concentrations of NDF was opposite the effects observed on digestibility of those fractions (i.e., removing contamination reduced the concentration of NDF but increased the digestibility of NDF). The same was true for ROM. Therefore, the effects of method on the concentration of digestible NDF or digestible ROM were generally less than the effect on concentrations or digestibility (Tables 2 and 3). Because summative energy equations (e.g., NRC, 2001) use concentrations of digestible matter (i.e., both digestible NDF and digestible ROM), NDF method had little effect on the final estimation of digestible energy. On average for the diets in Tables 2 and 3 , the sum of digestible NDF and $\mathrm{ROM}$ was equal (30.5\% of DM) for uncorrected NDF and full correction of NDF. In the worst case (by-product diets in Table 2), the difference between NDF methods for the sum of digestible NDF and ROM was $<0.1 \%$ of DM.

In addition to determining whether NDF method affected digestibility of NDF and ROM, we evaluated whether method would affect statistical interpretation of dietary treatment effects. If the $P$-value for significance was set at $P<0.05$, different conclusions may have been reached in experiment 1 . Mineral source affected $(P<0.05)$ NDF digestibility but did not affect $\mathrm{NDF}_{\text {om }}, \mathrm{NDF}_{\mathrm{cp}}$, or $\mathrm{NDF}_{\text {om }+\mathrm{cp}}$ digestibility (Table 4). However, method did not affect interpretation of the effect of fiber source on NDF digestibility; by-product diets had greater $(P<0.05)$ NDF digestibility than forage diets regardless of method. For experiment 2, the same conclusion relative to NDF digestibility was reached regardless of NDF method (i.e., hybrid did not affect NDF or ROM digestibility; Table 2). However, different treatment conclusions may have been reached relative to ROM digestibility. Based on the limited number of diets we evaluated, treatment inferences were similar for the different measures of NDF, but more diets with greater or more variable amounts of NDI-ash and NDICP should be investigated.

\section{Estimating True Digestible ROM}

For a nutrient fraction to be incorporated into a summative energy equation, its true digestibility and contribution to metabolic fecal excretion must be known. The Lucas test can be used to estimate true digestibility when a fraction displays nutritional uniformity over a range of feedstuffs or diets and has a nonnegative metabolic fecal content and a true digestibility <1 (Lucas, 1964; Van Soest, 1994). The full data set (10 digestibility experiments, 38 treatments; Table 6 ) was used to estimate the true digestibility coefficient of ROM (i.e., the slope) and metabolic fecal ROM (i.e., Y-intercept). When random effects of experiment and period within an experiment were included in the model, the Lucas test confirmed that ROM behaved as a nutritionally uniform fraction (Figure 1; Table 7). The Y-intercept was negative and different from zero $(P<$ 0.01 ), indicating that ROM has a significant metabolic fecal component. Starch and NFC also approximated nutritionally uniform fractions, but true digestibility and the metabolic fecal fraction differed between the 3 fractions (Table 7).

Metabolic fecal excretion of ROM was greater $(P<$ 0.01) than that for NFC (Tables 6 and 7). In theory, the metabolic fecal extraction of NFC and ROM should be essentially the same because starch does not have a metabolic fecal component. However, the estimates were statistically different $(P<0.01)$. The lower intercept for NFC compared with ROM could in part be a statistical issue. The NFC intercept has a large standard

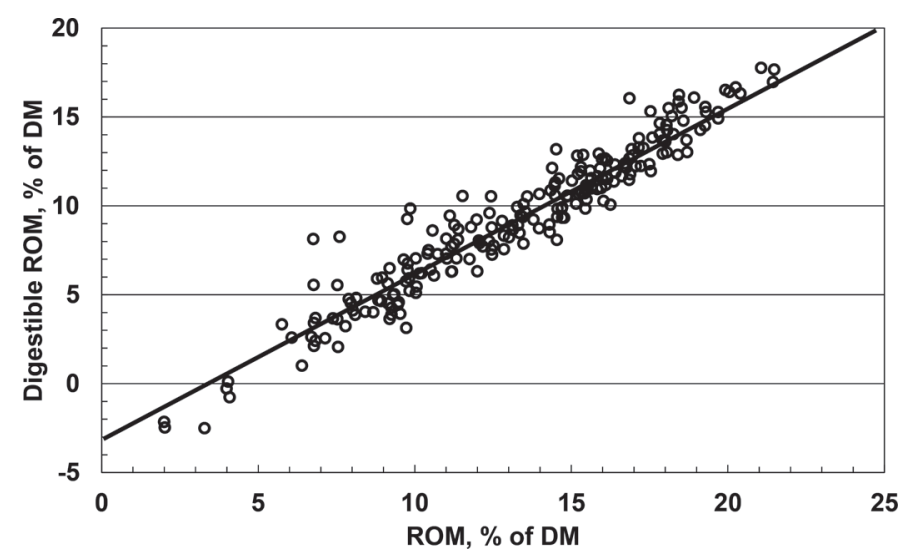

Figure 1. Relationship between residual OM (ROM) and digestible ROM concentrations ( $\%$ of DM) using the standard NDF method of the cumulative data set $(\mathrm{Y}=-3.43+0.961 \mathrm{X})$. Each point represents a cow period $(\mathrm{n}=214)$ and is adjusted for random effects of experiment and period within an experiment (St-Pierre, 2001). 
TEBBE ET AL.

Table 7. Lucas test ${ }^{1}$ for the full data set and data from experiments 1 and 2

\begin{tabular}{|c|c|c|c|c|c|}
\hline Item & Intercept $^{2}$ & SEM & Slope $^{3}$ & SEM & $\mathrm{BIC}^{4}$ \\
\hline \multicolumn{6}{|l|}{ Full data set ${ }^{5}$} \\
\hline Digestible $\mathrm{ROM}^{6}$ & $-3.43^{\mathrm{a}}$ & 0.295 & $0.961^{\mathrm{a}}$ & 0.021 & 688 \\
\hline Digestible NFC ${ }^{6}$ & $-2.08^{\mathrm{b}}$ & 0.800 & $0.903^{\mathrm{b}}$ & 0.020 & 806 \\
\hline Digestible starch $^{7}$ & $-0.17^{\mathrm{c}}$ & 0.359 & $0.931^{\mathrm{ab}}$ & 0.013 & 578 \\
\hline \multicolumn{6}{|l|}{ Experiments 1 and $2^{8}$} \\
\hline Common intercept & -3.76 & 0.604 & & & 204 \\
\hline Digestible ROM & & & $0.985^{\mathrm{a}}$ & 0.032 & \\
\hline Digestible $\mathrm{ROM}_{\mathrm{om}}$ & & & $0.909^{\mathrm{b}}$ & 0.032 & \\
\hline Digestible $\mathrm{ROM}_{\mathrm{cp}}$ & & & $0.938^{\mathrm{ab}}$ & 0.031 & \\
\hline Digestible $\mathrm{ROM}_{\mathrm{om}+\mathrm{cp}}$ & & & $0.874^{\mathrm{b}}$ & 0.025 & \\
\hline
\end{tabular}

${ }^{a-c}$ Values in the same column and data set followed by different superscripts are significantly different $(P<$ $0.05)$.

${ }^{1}$ Regression of dietary concentration and digestible concentration (\% of DM) of a nutrient.

${ }^{2}$ The estimate of the metabolic fecal content $(\mathrm{g} / 100 \mathrm{~g}$ of DMI).

${ }^{3}$ An estimate of the true digestibility coefficient.

${ }^{4}$ Bayesian information criterion.

${ }^{5}$ The full data set $(\mathrm{n}=214)$ using the standard NDF method.

${ }^{6}$ Residual OM $(\mathrm{ROM})=\mathrm{NFC}-$ starch. NFC $(\%$ of $\mathrm{DM})=100-\% \mathrm{CP}-\%$ long-chain fatty acids $-\%$ ash $-\% \mathrm{NDF}$.

${ }^{7}$ Y-intercept was not different from zero $(P<0.65)$.

${ }^{8}$ Experiments 1 and 2 data set measuring NDF using all 4 methods $(\mathrm{n}=47) \cdot \mathrm{ROM}_{\mathrm{x}}(\%$ of $\mathrm{DM})=100-\%$ $\mathrm{CP}-\%$ long-chain fatty acids $-\%$ ash $-\%$ starch $-\% \mathrm{NDF}_{\mathrm{x}}$, where $\mathrm{x}=\mathrm{NDF}$ method.

error (SE divided by the intercept is 4.5 times greater for NFC than for ROM) and has a greater extrapolation distance to zero than does ROM. The overall fit as assessed with the Bayesian information criterion was better for ROM and starch compared with NFC. The combination of better fit and smaller pool size (i.e., concentration in the diet) for ROM compared with NFC should result in more precise estimates of energy when incorporated into summative equations.

The NRC (2001) true digestibility coefficient of $\mathrm{NFC}$ at maintenance intake was set at 0.98 , which is substantially higher than true digestibility of NFC in this experiment (Equation 4; Table 7). Van Soest (1994) and Girard and Dupuis (1988) reported that true digestibility of NFC can range from 0.83 to 0.98 depending on intake. The average DMI in this data set was approximately 3.5 times maintenance (Table 6 ). After applying the NRC (2001) discount, the estimated true digestibility of NFC in our data set approximated the NRC (2001) value. Variation is partially caused by intake, but variation in starch digestibility (Ferraretto et al., 2013) also contributes to the variation in NFC digestibility. Many of the components of ROM, such as organic acids and sugars, should be essentially completely digested, which could explain the greater true digestibility of ROM compared with NFC (Table 7). However, other components, such as waxes, would be poorly digested, suggesting that our estimate of true digestibility of ROM could be too high.

In the data set measuring ROM using 4 different NDF methods, all intercepts were different from zero
$(P<0.05)$, but method did not affect $(P>0.19)$ estimated metabolic fecal ROM (Table 7). A common intercept was then calculated $(-3.78)$ and was similar to the value obtained for the full data set (Equation 3; Table 7). However, method did affect $(P<0.01)$ the estimates of true digestibility (Table 7 ). Estimated true digestibility of ROM calculated with NDF corrected for ash or CP contamination was lower than that for ROM calculated using uncorrected NDF (Figure 2).

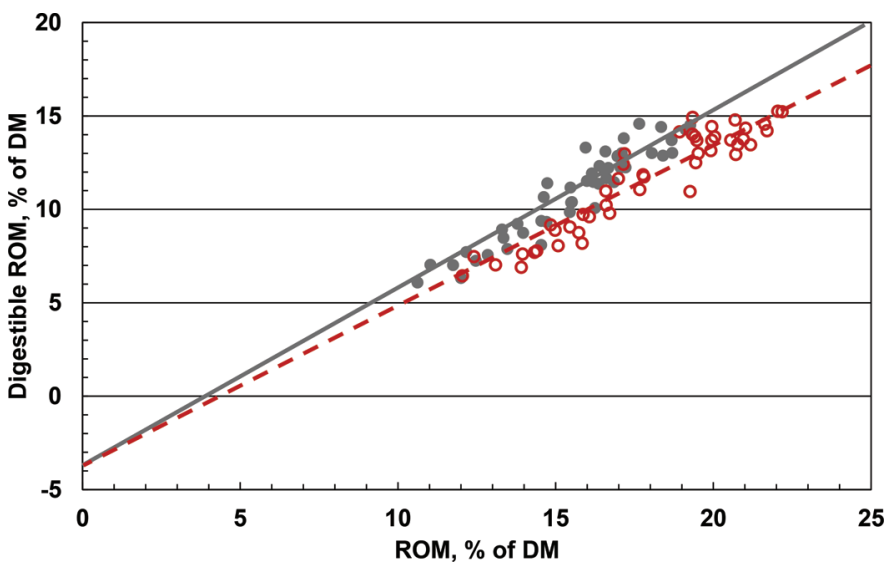

Figure 2. Relationship between residual OM (ROM) and digestible ROM concentrations (\% of DM) using the standard NDF (filled circle, solid line, online gray; $\mathrm{Y}=-3.76+0.985 \mathrm{X})$ and the ash- and $\mathrm{CP}-$ free NDF (open circle, dashed line, online red; $\mathrm{Y}=-3.76+0.874 \mathrm{X}$ ) methods. Each point represents a cow period $(\mathrm{n}=47)$ and is adjusted for random effects of experiment and period within an experiment (StPierre, 2001). Color version available online. 
This suggests that ash and CP contaminated the fiber as it passed through the digestive tract, resulting in a decrease in apparent fecal ROM when NDF is not corrected for ash and CP contamination.

Correcting NDF for ash and CP contamination should result in the most accurate estimates of diet energy because it avoids double subtraction of NDI-ash and NDICP and eliminates the error in measuring NDF digestibility caused by contamination of the fraction as it flows through the digestive system. This correction is also biologically relevant because ash does not contribute to digestible energy. However, the number of diets available to generate Equation 9 was limited, resulting in a greater standard error and less confidence in the coefficients than the equation using NDF in the full data set (Equation 3). Quantitatively, the differences in estimating digested ROM will usually not be great between Equations 3 and 9. For example, the greatest difference between $\mathrm{ROM}$ and $\mathrm{ROM}_{\mathrm{om}+\mathrm{cp}}$ concentrations was observed for the by-product diet in experiment 1 (Table 2), but the estimated digestible $\mathrm{ROM}_{\mathrm{om}+\mathrm{cp}}$ was only about $4 \%$ greater than estimated digestible ROM.

\section{Integrating ROM into Energy Models}

Incorporating ROM into the summative equation used by NRC (2001) requires replacing the NFC term $(0.98 \times \mathrm{NFC}$, where NFC is expressed as percentage of $\mathrm{DM}$ and is calculated using $\mathrm{NDF}_{\mathrm{cp}}$ ) with a term for starch and a term for ROM:

$$
\begin{gathered}
(\text { starch digestibility } \times \text { starch })+0.96 \\
\times \text { ROM }- \text { metabolic fecal ROM }
\end{gathered}
$$

or

$$
\begin{gathered}
(\text { starch digestibility } \times \text { starch })+0.87 \times \mathrm{ROM}_{\mathrm{om}+\mathrm{cp}} \\
- \text { metabolic fecal } \mathrm{ROM}_{\mathrm{om}+\mathrm{cp}} .
\end{gathered}
$$

Note that the total metabolic fecal fraction would comprise more than ROM (e.g., metabolic fecal nitrogen) but that the ROM contribution to the metabolic fraction would vary depending on NDF method.

\section{CONCLUSIONS}

When correcting for ash and CP in NDF and ROM fractions, their digestibilities increased and decreased, respectively, and the effects were greater for diets based on by-products (i.e., significant diet interaction). Removing starch from NFC to produce the ROM fraction increased the precision for estimating true digestibility and metabolic fecal excretion. Correcting NDF for ash and protein contamination reduced the true digestibility of the resulting ROM fraction. The data provided in this paper allow for replacing NFC with starch and ROM in summative energy equations, but the equation used depends on whether NDF was corrected for ash and protein contamination. Additional data on the apparent digestibility of $\mathrm{ROM}_{\mathrm{om}+\mathrm{cp}}$ are needed to increase the precision of the estimated true digestibility and metabolic fecal fraction.

\section{ACKNOWLEDGMENTS}

The authors thank Donna Wyatt (The Ohio State University) for assistance in conducting many of the assays and calculations and for organizing the data. They also thank Kevin Miller and the rest of the Ohio Agriculture Research and Development Center Krauss Dairy Farm staff for animal care and assistance during the digestion trials.

\section{REFERENCES}

Allen, M. S., and P. Piantoni. 2014. Carbohydrate nutrition: Managing energy intake and partitioning through lactation. Vet. Clin. North Am. Food Anim. Prac. 30:577-597.

Crocker, L. M., E. J. DePeters, J. G. Fadel, S. E. Essex, H. PerezMonti, and S. J. Taylor. 1998. Ash content of detergent fibers in feeds, digesta, and feces and its relevance in fiber digestibility calculations. J. Dairy Sci. 81:1010-1014.

DePeters, E. J., J. G. Fadel, and A. Arosemena. 1997. Digestion kinetics of neutral detergent fiber and chemical composition within some selected by-product feedstuffs. Anim. Feed Sci. Technol. $67: 127-140$

Faulkner, M. J., and W. P. Weiss. 2017. Effect of source of trace minerals in either forage- or by-product-based diets fed to dairy cows: 1. Production and macronutrient digestibility. J. Dairy Sci. https:// doi.org/10.3168/jds.2016-12095.

Ferraretto, L. F., P. M. Crump, and R. D. Shaver. 2013. Effect of cereal grain type and corn grain harvesting and processing methods on intake, digestion, and milk production by dairy cows through a meta-analysis. J. Dairy Sci. 96:533-550.

Firkins, J. L. 2006. Starch digestibility of corn - Silage and grain. Pages 107-119 in Proc. Tri-State Nutr. Conf., Ft. Wayne, IN. The Ohio State University, Columbus.

Girard, V., and G. Dupuis. 1988. Effect of structural and chemical factors of forages on potentially digestible fiber, intake, and true digestibility by ruminants. Can. J. Anim. Sci. 68:787-799.

Hall, M. B. 2003. Challenges with nonfiber carbohydrate methods. J. Anim. Sci. 81:3226-3232.

Hall, M. B. 2014. Selection of an empirical detection method for determination of water-soluble carbohydrates in feedstuffs for application in ruminant nutrition. Anim. Feed Sci. Technol. 198:28-37.

Kagan, I. A., B. H. Kirch, C. D. Thatcher, C. D. Teutsch, and R. S. Pleasant. 2014. Chromatographic profiles of nonstructural carbohydrates contributing to the colorimetrically determined fructan, ethanol-soluble, and water-soluble carbohydrate contents of five grasses. Anim. Feed Sci. Technol. 188:53-63.

Krishnamoorthy, U., T. V. Muscato, C. J. Sniffen, and P. J. Van Soest. 1982. Nitrogen fractions in selected feedstuffs. J. Dairy Sci. $65: 217-225$.

Lucas, H. L. 1964. Stochastic elements in biological models; Their sources and significance. Pages 355-385 in Stochastic Models in 
Medicine and Biology. J. Gurland, ed. University of Wisconsin Press, Madison.

Mertens, D. R. 2002. Gravimetric determination of amylase-treated neutral detergent fiber in feeds with refluxing in beakers or crucibles: Collaborative study. J. AOAC Int. 85:1217-1240.

Mertens, D. R. 2016. Ash-free fiber (aNDFom): Why the change and what are the consequences? Pages 96-100 in Proc. 4-State Applied Nutr. Mgmt. Conf., La Crosse, WI. Midwest Plan Service Iowa State University, Ames, IA.

National Research Council. 2001. Nutrient Requirements of Dairy Cattle. 7th rev. ed. Natl. Acad. Sci., Washington, DC.

Nordheim-Viken, H., and H. Volden. 2009. Effect of maturity stage, nitrogen fertilization and seasonal variation on ruminal degradation characteristics of neutral detergent fibre in timothy (Phleum pratense L.). Anim. Feed Sci. Technol. 149:30-59.

SAS Institute. 2015. SAS/STAT User's Guide. Version 9.4. SAS Inst. Inc., Cary, NC.

St-Pierre, N. R. 2001. Invited review: Integrating quantitative findings from multiple studies using mixed model methodology. J. Dairy Sci. 84:741-755.
Valk, H., I. E. Kappers, and S. Tamminga. 1996. In sacco degradation characteristics of organic matter, neutral detergent fibre and crude protein of fresh grass fertilized with different amounts of nitrogen. Anim. Feed Sci. Technol. 63:63-87.

Van Soest, P. J. 1994. Nutritional Ecology of the Ruminant. Cornell University Press, Ithaca, NY.

Weiss, W. P., H. R. Conrad, and W. L. Shockey. 1986. Digestibility of nitrogen in heat-damaged alfalfa. J. Dairy Sci. 69:2658-2670.

Weiss, W. P., N. R. St-Pierre, and L. B. Willett. 2009. Varying type of forage, concentration of metabolizable protein, and source of carbohydrate affects nutrient digestibility and production by dairy cows. J. Dairy Sci. 92:5595-5606.

Weiss, W. P., and D. J. Wyatt. 2000. Effect of oil content and kernel processing of corn silage on digestibility and milk production by dairy cows. J. Dairy Sci. 83:351-358. 